\title{
Research On Enterprise Investment Decision Method Based On Circular-Economy
}

\author{
Junwei Miao \\ Department of Economic Management, North China Electric Power University, Baoding, 071003, \\ China
}

1506355739@qq.com

Keywords: circular-economy; investment decision; sustainable development

\begin{abstract}
Developing cycle economic is a requirement of the sustainable development of enterprises in our country. It is also the inevitable trend of the development of China's economy. However, the traditional management accountant investment decision method only considers the impact of investment item operation on the state of operation and financial result in enterprises. This paper studies investment decision method under circular economy. First, disadvantages of current investment decision-making model are introduced. Second, goals and principles of Investment decision method based on circular-economy are studied. Then, investment decision methods that are total cost assessment, stakeholder value assessment and multi criteria evaluation method based on circular-economy are analyzed. Last, Selection of investment decision-making method based on circular-economy is studied. It hopes to offer the scientific basis for enterprise's investment decision under circular economy background.
\end{abstract}

\section{Introduction}

Developing circular economy vigorously and building a resource-conserving and environment-friendly society are considered as basic strategy in the eleventh five-year plan. To develop circular economy, protect resources and environment and implement sustainable development strategy, traditional investment model must be changed. Environmental cost and benefit are not put into consideration in current investment decision-making model. It ignores the factors in cyclic economy conditions, for example, environment protection, resources utilization and social sustainable development, there are still some defects. It is not conducive to the long-term development of enterprises and will destroy the harmony of man and nature. Environmental factors must be considered when enterprise makes investment decisions under circular economy. Thus, it will protect natural environment and will have a positive impact on the health of human life and the sustainable development of social economy.

Because current environment is worsening and enterprises do not consider the environmental factors, enterprise investment decision method under circular economy is researched in this paper. Investment decision-making system under circular economy can not only evaluate the investment project and offer the scientific basis for enterprise's investment decision, at the same time; it also can reflect the impact of the investment projects in social and economic development process on the environment and society

\section{Concept Of Circular Economy}

Circular economy is a kind of new economy form and economic development model and its meaning is using resource in environmentally friendly ways, combining environmental protection and economic development organically and putting human production activities into the natural cycle. Resource circulation is the main characteristic and all the raw materials and energy are used reasonably and efficiently in the cycle of economic to control the influence degree of economic activities on the natural environment as small as possible.

Circular economy is an industry revolution from market-driving product industry to ecological rule green industry. And it is an ecological economy with the characteristic of closed loop flow. 
Unity of economic benefit, environmental benefit and social benefit can be achieved under circular economy. The intension of circular economy includes three basic principles: reduce, reuse and recycle. It is shown in figure 1.

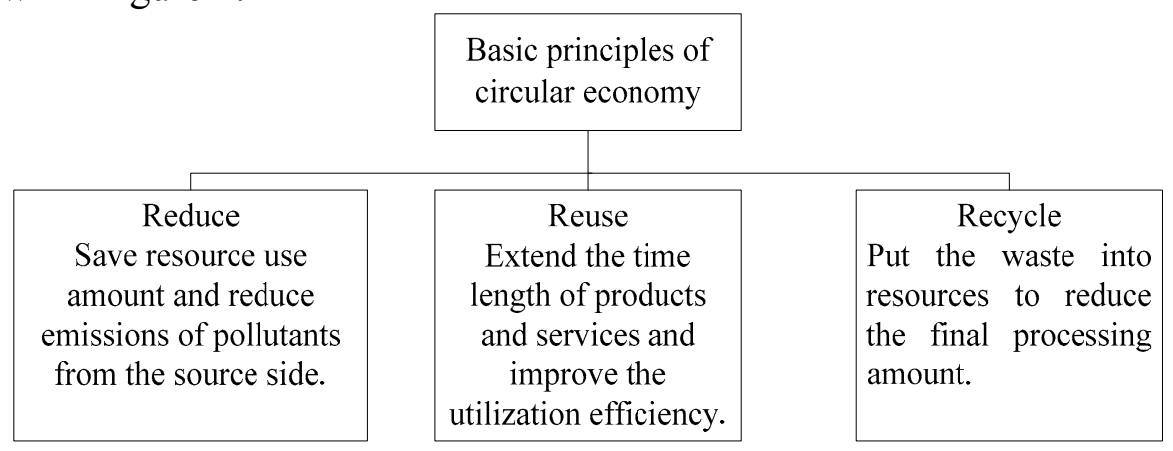

Fig.1 Three basic principles of circular economy

\section{Goals And Principles Of Investment Decision Method Based On Circular-Economy}

Goals Of Investment Decision Method Based On Circular-Economy.Circular-economy should realize the economic effect and the environment effect and the social benefit unified. Therefore, the goals of investment decision method based on circular-economy include enterprise financial income goal, ecological environment quality goal and social development goal (shown in figure 2.).

Enterprise financial income goal is the basic goal and it includes profitability analysis, solvency analysis and target contrast analysis of projects. Ecological environment quality goal means pay attention to the effects of project on environmental quality when enterprise producing and operating. Social environment factors have impact on project costs and benefits and the implementation of project will bring positive or negative influence to society. So making investment decision based on circular-economy must consider social development.

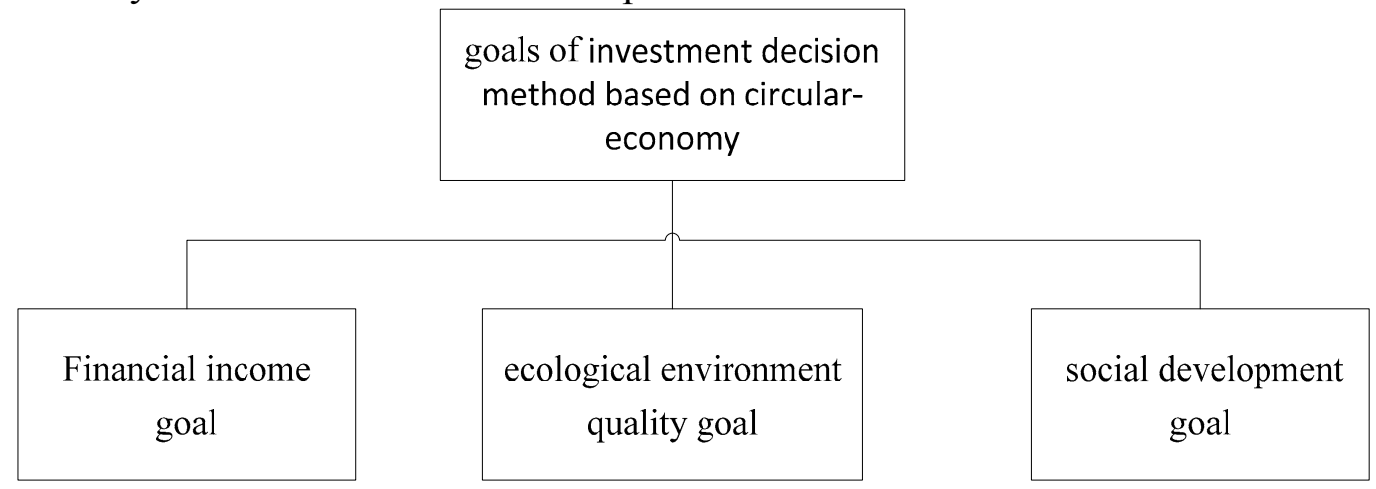

Fig.2 Goals of investment decision method based on circular-economy

Principles Of Investment Decision Method Based On Circular-Economy.Investment decision method based on circular-economy must follow some principles, which are cost-benefit principle, long-term and progressive principle, social principle and lay equal stress on monetary measurement and non-monetary measurement principle based on circular economy (shown in figure 3.). 


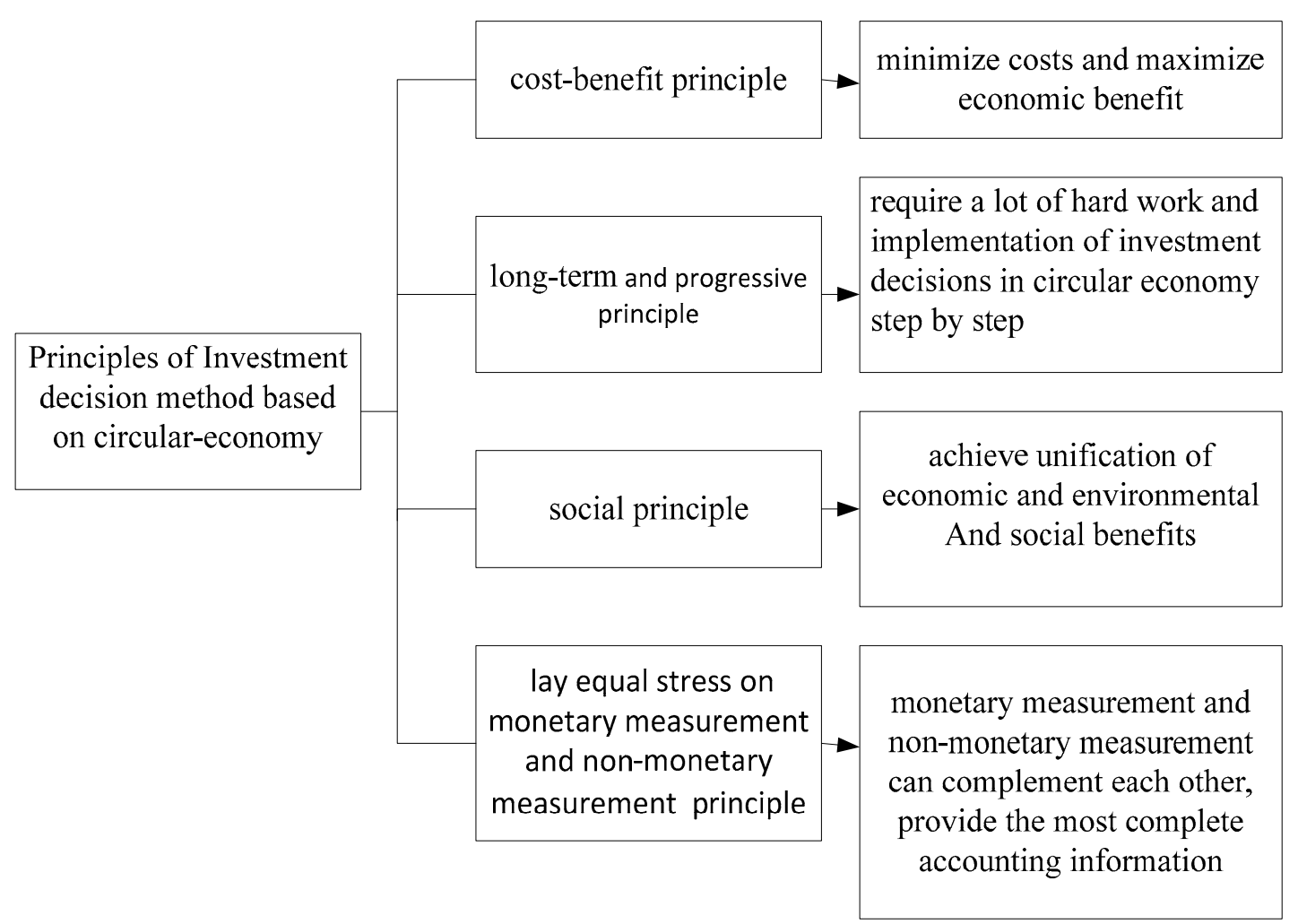

Fig.3 Principles of investment decision method based on circular-economy

\section{Investment decision method based on circular-economy}

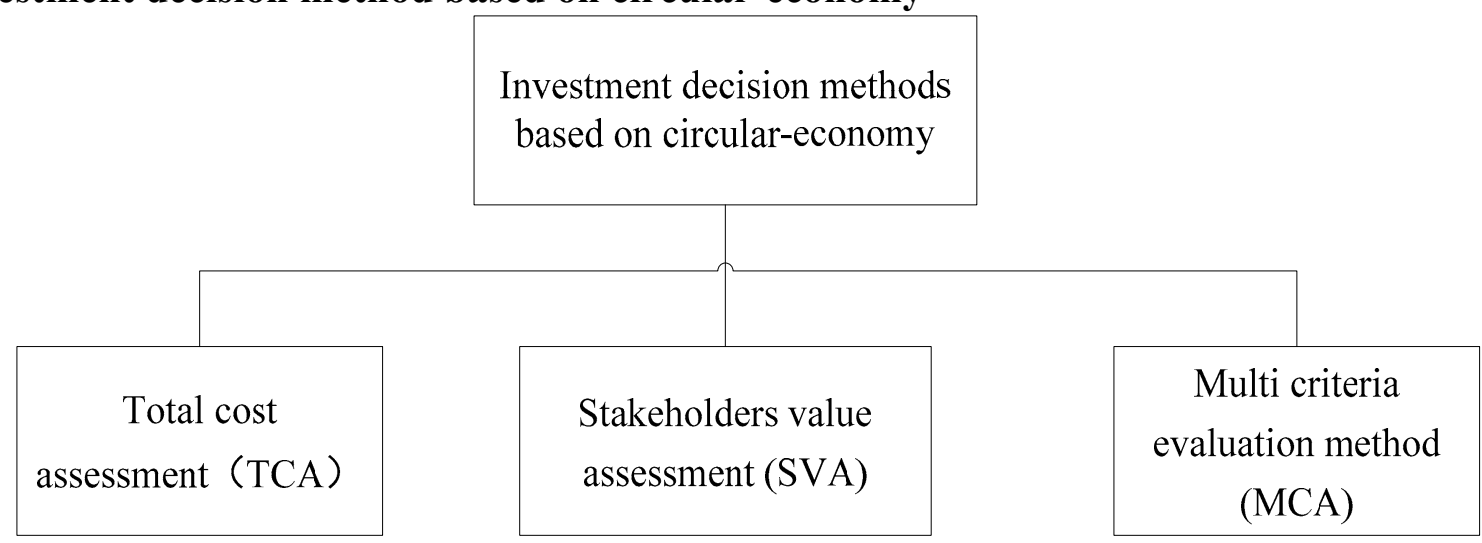

Fig.4 Investment decision methods based on circular-economy

On the basis of above analysis, investment decision should follow cost-benefit principle, long-term and progressive principle, social principle, lay equal stress on monetary measurement and non-monetary measurement principle based on circular economy. On basis of these principles and research literature at home and abroad, there are several commonly used enterprise investment decision method based on circular-economy. In this paper, total cost assessment, stakeholder value assessment and multi criteria evaluation method are studied in detail (shown in figure 4.).

Total Cost Assessment ( TCA) .Total cost assessment (TCA) was designed by the EPA branch, New Jersey. It is a method considering environmental cost comprehensively in the capital budgeting analysis and conducts long-term comprehensive financial analysis on all the costs and benefits of project. P2 / Finance software was developed by EPA and Tellus Institute to establish an effective data center. TCA includes internal and external environmental costs, as shown in table 1.

Comparing with the traditional capital evaluation method, the biggest improvement of total cost assessment extending the time of evaluation and the scope of benefits and costs. Total cost assessment does not affect the enterprise's profit ability, but it can list the composition of projects' cost and benefit. So, some projects that is good for environment can also get investment. 
Table 1 Contents of the environmental cost

\begin{tabular}{c|c}
\hline internal environment cost & external environmental cost \\
\hline Waste management costs \\
Renovation costs \\
Execution cost \\
Discharge fee \\
Environment training fee \\
Natural resources consumption \\
Noise pollution \\
Environment research and development cost \\
Legal costs and penalties \\
Environment insurance fee \\
Waste water and exhaust emissions \\
Long-term waste \\
Government regulation risk changes in the future \\
Asset damage risk
\end{tabular}

Stakeholders Value Assessment (SVA).Enterprise management activity is associated with a growing number of stakeholders nowadays and these stakeholders have increasingly profound impact on the business capital projects. It increases the uncertainty of decision-making and has crucial impact on the success or failure of the investment decision. Stakeholder value assessment refers to consider the assigning value by stakeholders in advance in the decision making process, combine financial analysis with non-financial analysis, provide support for decision making, understand all the value of the solution and avoid the influence of uncertainty. According to different costs and benefits, Stakeholder value assessment measures the risk respectively and overcomes the disadvantages that regard cost risk and benefit risk as the same in traditional financial index evaluation. Meanwhile expectations of stakeholders are considered when determining the weight and then financial indicators weights will be relatively reduced and at the same time environmental performance indicators weight are likely to increase. So, it can coordinate decision results and the requirements of stakeholders.

Multi Criteria Evaluation Method (MCA).Multi criteria evaluation method can help the company systematically evaluate project according to the different or immeasurable multiple criteria. First, give the corresponding weights in accordance with the importance of goals. Then, grade the selected projects according to different standards. Last, calculate total score of the selected projects and choose a better one on basis of calculation results. The main goal of multi criteria evaluation method is combining economic analysis, social analysis and environmental impact assessment closely. For single decision and mean decision enterprises, multi criteria evaluation method could help them seek to a best project. But this method also has its drawback that is hard to get an optimal solution satisfy all stakeholders because the importance of different stakeholders to the project goal is different.

\section{Selection Of Investment Decision-Making Method Based On Circular-Economy}

Under circular economy mode, enterprise will be facing not just financial pressure, but also facing the pressure of environment protection and social responsibility. With the promotion of circular economy and sustainable development, Enterprise must consider the influence of the environment in the process of investment decision. While environmental factors are not taken into account in traditional investment evaluation methods, we must change traditional investment decision method to put circular economy mode into investment decision.

The methods studied above have their own advantages and disadvantages. Total cost assessment reflects the environmental costs and benefits fully by expanding the scope of cost and extending the time span. Stakeholder value assessment combines financial evaluation with standard evaluation and risk evaluation methods to help decision-maker make reasonable strategic decision. Multi 
criteria evaluation method combines financial index and environmental indicators and other indicators to provide a quantitative basis for solution sorting.

Circular economy emphasizes the sustainable development of economic, environment and society. So it is necessary for enterprise to take account of economic and social and environmental benefits when making investment decisions, namely multi-objective decision should do. Therefore, multi criteria evaluation method has been widely applied. Constructing a enterprise long-term investment decision multi-objective evaluation model can achieve the sustainable development goal that integrates cycle economics pattern with enterprise environmental management accounting investment decisions

\section{Summary}

Traditional economic growth model promotes the development of economy, but also brings damage to nature. Speeding up developing circular economy, the resource-efficient society and promote harmonious development must be built between human and nature. Developing circular economy project must adopt a more scientific investment decision method in order to maintain the scientific correctness of enterprise investment decision.

\section{References}

[1] Cuixiang Tian, Shuqing Lv. Enterprise project investment decision-making case analysis considering environmental factors [J].Friends of Accounting, 2012(28):63-65.

[2] Yongchen Li. Research on enterprise environmental accounting [M].Beijing:China Renmin University Press,2005,88-94.

[3] Taylor, Peter J, Catalano, Gand Walke, D.R.F. (2002) ExPloratory Analysis of the World City Network.Urban Studies, 2002(39).

[4] Takaoshi Shinduma, On the Seeond-best poliey Of Household's Waste Recyeling, Environmental and Resouree Eeonomies,2003,P77-95.

[5] Junhui Yin. Environmental management accounting investment decision-making method based on circular economy [J]. Modern finance and economics, 2009(3):5-39.

[6] Jinyu Chen. Research on limitations of enterprises develop circular economy in our country [D]. Market Modernization, 2007 (02X): 34-35.

[7] Clerc M. Discrete Particle Swarm Optimization Illustrated by the Traveling Salesman Problem. 2000.

[8] R.C.Eberhart, Y.Shi. Comparing inertia weights and constriction factors in particle swarm optimization. In Proceedings of IEEE International Congress on Evolutionary Computation, 2000: 84-88.

[9] J.Kennedy, R.Mendes. Population structure and particle swarm performance. Proceeding of IEEE conference on Evolutionary Computation, 2002: 1671-1676. 